\title{
The Possibility of Promoting User Participation in Working with High-risk Youth
}

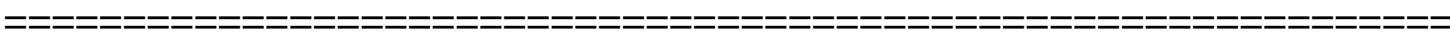

The concept of user participation has been popular in social work since the 1970s. In view of the increased discussion on user-led practice in social work, it is not surprising to see that the concept of user participation has surged to a position of prominence in the professional discourse of social workers. According to Atkinson and Elliott (1994), the term 'user' implied an active participation on the part of the individual (client) with the service and it is better than using the terms 'client', ‘consumer’ or 'recipient’ (Atkinson and Elliott, 1994:157). Generally speaking, most social workers agree on the value of encouraging clients' involvement in the helping process. The practicality of this concept, especial in working with high-risk youth, who are usually perceived as immature, having low self-esteem, lack of coping ability and self-control (Jessor et al., 1991; McWhirter et al., 1998), deserves further exploration.

In order to investigate this issue, a study was conducted in the field of outreaching social work (OSW) (detached youth work) with high-risk youth in the streets in Hong Kong. This paper reports on this qualitative study, exploratory in nature, that was carried out in three of the 34 OSW teams in Hong Kong.

As background to this study, introduction of the OSW service in Hong Kong, the characteristics of the high-risk youth, especially in the Hong Kong context, and the conceptions of user participation is given next. 


\section{Outreaching Social Work Service}

Outreaching Social Work service operates in teams of professionally trained social workers. It aims to establish contact with at-risk young people, who are unattached with the conventional social systems (e.g. family and school) and are vulnerable to undesirable influences, in places they are known to frequent (e.g. street corner, playground, fast-food restaurant, billiard room, etc.). The ultimate goal of the service is 'to provide counselling, guidance and other forms of service to help them overcome their problems, develop their potential and become socially re-integrated' (Social Welfare Department, 1998:51). There are currently 34 Outreaching Social Work teams serving different priority districts/communities of the territory with higher juvenile crime rate and unserved youth population. Depending on the population size of the districts/communities served, there are small teams and large teams. The full strength of a small team is 5 social workers while that of a large team is 10. The OSW teams studied in this investigation belonged to a non-governmental organization and were all large teams.

The working stages with the clients in OSW service can generally be classified into three stages: engagement, helping and termination stages. For clients in the engagement stage, the workers usually know them for a rather short period of time (within 3 months). At this stage, workers are consciously trying to establish a more trusting relationship with them for rapport building in order to engage them in the helping stage. In the helping stage, clients usually have established trust with their workers who help the clients verbalize their problems and encourage and support them to face/handle their problems positively. This stage may last for 2 to 3 years. 
The final stage of working with the clients is the termination stage. At this stage, clients usually have been able to face/solve their problems positively. The major focus of the workers is to help clients evaluate and consolidate their learning from the helping process hoping that they can transfer these learning into other contexts in the future after the helping process ends.

\section{Characteristics of High-risk Youth}

McWhirter et al. (1998) defined 'at-risk'/'high-risk' as denoting 'a set of presumed cause-and-effect dynamics that place (a) child or adolescent in danger of negative future events' (McWhirter et al., 1998:7). The encountering of various problems, such as physical and sexual abuse, suicide, gang membership, substance abuse, homelessness and dropping out from school, have been identified as serious issues met by the high-risk youth (Capuzzi and Gross, 1996). A multitude of unfavourable traits has been suggested as characteristics of the high-risk youth. These include low resiliency, low self-esteem, lack of communication skills, inability to cope with stress, lack of self-control ability and lack of purpose in life (Jessor et al., 1991; McWhirter et al., 1998). In Hong Kong, high-risk youth have been suggested as sharing an anti-social subculture and exhibiting delinquent/pro-delinquent behaviours (Lee, 1994). An indigenous study had reported that the high-risk youth were subject to undesirable influence from the peers, lacking family care and having weak bonding with school/work (Wong, 1997). The joining of Triad gangs, hence sharing the Triad subculture, was also common among these young people (CSWYISC, 1999). Thus, it is evident that, in terms of all the problems and characteristics of the high-risk youth, their ability to understand their problems and 
suggest ways to solve them is in doubt. This further leads to skepticism on the ability of the high-risk youth to 'participate' in the helping process that they receive from social workers.

\section{Conceptions of User Participation}

The trend of promoting client/user participation has had considerable influence on social work practice. Most social workers will not deny the values of promoting clients'/users' involvement in the helping process. The development of the concept and promotion of user participation has been mainly influenced by the following three issues.

Awareness of User Participation Rights: A document of the British Association of Social Workers (BASW, 1980) indicated that the concept of client (user) participation had already been widespread in all social work activities in the United Kingdom from the late 1970s. In the United States, the NASW Code of Ethics also states that the 'social worker should make every effort to foster maximum self-determination on the parts of clients' (NASW, 1993:1). It has been recommended that the "Prometheus Principle” should govern client participation (Fischer and Brodsky, 1978). The principle states that 'knowledge, power and responsibility should be shared by all parties engaged in offering human services with those receiving such services' (Fischer and Brodsky, 1978:ix). This indicates that the autocracy of professional power should be revised toward a democracy of full client/user partnership. All these indicate the growing awareness of rights of service users to participate in the 
helping process and that social workers should make every effort to foster maximum participation of service users.

Promotion of Clients' Empowerment: The trend of clients' empowerment also has significant influence on the promotion of user participation. Empowerment is defined as 'the means by which individuals, groups and communities become able to take control of their circumstances and achieve their own goals, thereby being able to work towards helping themselves and others to maximize the quality of their lives' (Adams, 1996:5). Brohman (1996) articulated the relationship of empowerment and user participation by suggesting that 'the concept of participation as empowerment comes close to the notion of development as fulfillment of human potentials and capabilities’ (Brohman, 1996:265). Croft and Beresford (1994) pointed out the aim of partnership and participation is to empower people. Therefore, to promote user participation is an empowerment process through which they are offered opportunities to take control of their circumstances and develop their potentials and capabilities in order to attain positive self-development.

Emphasis on Consumerism: Parallel to the development of user participation and the empowerment movement, consumerism has also been a prevailing concept in social work. Under the influence of "total quality management" in the business sector, social welfare agencies are picking up the language of consumerism and are talking about hearing the voice of the consumers and focusing on customers' needs (Martin, 1993; Gunther and Hawkins, 1996; Skelcher, 1996). Fundamentally, the doctrine of consumerism within human service systems is that 'individuals are more knowledgeable about their own needs and interests than professionals. When 
individuals redefine their role from that of client to that of consumer, their sense of control over their lives is elevated' (Tower, 1994:192).

\section{$\underline{\text { Kinds of User Participation }}$}

Parsloe (1990) had defined two aspects of participation, namely, expressive and developmental. The expressive aspect is much more ideological. It is the belief that 'people have a right to say in the services they receive'. The developmental aspect is 'a means of achieving greater individual fulfillment, personal development, self-awareness and some immediate satisfaction'. From her study, she concluded that enhancing client (user) participation was not a prohibition of social work professionalism, instead, clients' rights to make a choice of social work methods they received were promoted. In the present study, a focus has been given to exploring which of these two aspects of participation OSW workers emphasized more in their helping process with their clients (service users).

\section{The Study}

This was a qualitative study. Data for this study were collected through in-depth interviews with an interview schedule with fifteen OSW workers, 7 male and 8 female, randomly selected from three OSW teams. The interview schedule was constructed mainly to explore workers' understanding of the conceptions of user participation and how they implemented the concept in their practice. Two workers interviewed had been working in the service for two to three years, eight had been working in the service for three to five years and five had been working in the service for over five years. All of them were trained (registered) social workers in Hong 
Kong. Fifteen OSW male clients aged 14-19, who were cases of the teams, were also randomly selected for interviews using another interview schedule. The interview schedule was constructed mainly to explore clients' understanding of the conceptions of user participation and how they perceived their participation in the helping process. In order to increase the richness of the contents of the information and data collected, one of the criteria for selecting OSW workers to be interviewed was that they should have at least working in the field for two years. To preserve anonymity, worker respondents were assigned a serial code from W1 to W15. For the clients selected to be interviewed, five of them were in the engagement (preliminary working) stage, five were in the helping stage and five in their termination stage. Again, to preserve anonymity, client respondents were also assigned a serial code with E1 to E5 as clients in the engagement stage, H1 to H5 as clients in the helping stage and T1 to T5 as clients in the termination stage. The focuses of the interviews with the workers were on their understanding of the concept 'user participation', if they support the concept, and how they actually practise the concept in the service delivery process. For the clients, the interviews were also focused on exploring their understanding of the concept 'user participation', then their actual involvement/participation at different stages in the helping process was explored.

The fieldwork part of the study was conducted from February to May 1999. In order to ensure consistency of the data collection process, one of the authors was responsible for conducting all interviews with the worker respondents and client respondents. 


\section{Promotion of User Participation in Working with High-risk Youth: The Reality}

\section{Workers' Understanding of User Participation}

In response to the question on exploring their understanding of the concept 'user participation' in the helping process with their clients, all workers indicated that they understood the concept although they described it in different terms. They shared similar ideas that user participation is a way to maximize clients' commitment in decision making and actions in the helping process. For example:

If user participation is equal to the practice of increasing clients' understanding of their situations and helps them to define their changing process, it is important and needs to be promoted. (W11)

Seven workers (W1, W5, W6, W11, W13, W14 and W15) highlighted that the concepts of user participation were generated from the respect of self-determination and this was similar to Carroll's idea (1980). All fifteen workers stated that they followed social work values of upholding clients' rights to invite their opinions and make their own decisions, which is the basic ideology behind user participation. It was observed that all the respondents felt the concept 'user participation' applicable in the OSW service.

The respondents had similar ideas on user participation but their focuses of concern were different. Four respondents (W1, W3, W7 and W14) saw that user participation was the basic consumer right of clients (expressive aspect). Three (W12, W13 and W15) had continuing interest in clients' growth after involvement 
with them in the helping process (developmental aspect). There were three respondents (W8, W9 and W10) who were also concerned in both the expressive and developmental aspects of user participation (Parsloe, 1990).

\section{Workers’ Actual Practice in Promoting User Participation}

As all workers supported the promotion of user participation in working with their clients, their strategies of promoting user participation in the helping process with their clients were explored. The exploration in this area was further focused at three stages of the working process of the service, namely, the engagement stage, the helping stage and the termination stage.

Engagement Stage: It is significant to note that at the beginning of the working process, most workers would explain the service objectives of OSW and clarify their role as an OSW worker to their clients. This challenges the common belief that the OSW workers (detached youth workers) would conceal their identity at the beginning of the working process in order to reduce avoidance from those who do not like to be labeled as clients. Giving out their name cards was the customary way of establishing their roles. As one respondent put it,

The contents of the name card have a brief description of my work in the service, such as sharing, counseling, training, organizing activities and offering tangible help. It helps to increase client's understanding towards my service. (W10) 
However, informing the clients on their status and rights was not generally emphasized in the engagement stage. Ten workers reported that they would select a suitable moment to disclose to clients the opening and keeping of their case files. It would also depend on the relationship they had established with the clients and the sensitiveness of the clients. That leads to practices such as:

Although I know that informing clients about their status and keeping of their records are some prerequisites for promoting user participation, I think I do not have enough skills in explaining the details smoothly and tackling their resistance if they have any. (W1)

and

I will tell them their client status and the keeping of their case records if they are mature enough and I have established a stable relationship with them. (W7)

Findings revealed that, conceptually, most workers agreed on the importance of sharing the service objectives with the clients. Clients' knowledge of the worker's roles, and their client status and rights are regarded as fundamental for promoting user participation. However, in actual practice, workers reported some reservations in doing this at the engagement stage because,

Informing client status is a way to show worker's professional honesty and reduce future misinterpretation, but how to do it in the engagement stage is a difficult question. (W14) 
Most workers interviewed provided a brief introduction of the service and their roles as an OSW worker to their clients, but the practice of initially disclosing client status and keeping of records was not frequent. Strategic planning in sharing such information in the engagement stage was rare. The results reveal that in the engagement stage, most of the clients were not consulted whether they wanted to receive OSW service or not.

Helping Stage: In discussing their practice when the cases entered into the helping stage, only two workers reported that they would encourage their clients’ active involvement in the assessment and intervention process. Such difficulties pose a hindrance to the promotion of user participation in the service. The following responses from two workers revealed some common difficulties faced in working with high-risk youth at this stage.

When clients are deeply involved in and enthusiastic about Triad activities, I can feel their resistance in discussing the related undesirable influence with me. I have difficulty in sharing my assessment with them and motivating them to leave the Triad gang. (W5)

and

I have tried to invite some of my clients to discuss on their needs, goals and action plans, but they broke the appointments several times. I cannot afford to wait for them to participate in the assessment and I finished the assessments by myself. (W9)

Concerning the issue of case files, most workers were willing to let clients know 
their existence at this stage as opposed to the engagement stage. They were also then more willing to let clients have access to their own files as the following two extracts illustrate:

Sharing records with clients will increase their understanding towards their needs, the helping progress and their rights. This can enhance their participation. (W3)

and

Workers have spent a lot of effort in paperwork for assessing and recording the development of their clients. It is certainly an invaluable treasure to share them with respective clients. Also, clients will appreciate worker's effort in writing so much for them. I will allow my clients to comment on the contents of their case files and this can promote a closer working relationship among us. (W12)

It seems that OSW workers' beliefs about user participation was inconsistent with actual practice in the helping stage. In the formulation of assessment and intervention plans, the workers did not have a strong drive to involve clients in the process. They tended to focus more on their personal judgement and the actual results in implementing their plans, but overall they were more willing to let clients know the existence of and have access to their case files.

Termination Stage: All workers recognized that termination as an important stage in the helping process. They all stated that they would inform the clients about the termination as working objectives were achieved and invite their participation in 
evaluating the services provided. Nevertheless, there were differences in the methods they employed. Six respondents (W7, W8, W9, W10, W12 and W15) clearly told the clients about the termination of cases as terminating the working relationship with the OSW team before they carried out consolidation work with the clients on their experience in the helping process. One group would inform the clients about the termination and focus on the growth of clients and recognize their capability to be independent. The other group would try to use oral or non-oral means (such as cards) to inform clients or their family members about the termination. The results revealed that all workers believed the process of termination was useful in helping clients review their progress in the process and gave recognition to their success.

All workers considered termination as an appropriate time for consolidation work with the clients for helping them identify their strengths, recognize their growth and build up their confidence in facing their future. The use of non-oral tools such as case files (W3), questionnaire (W5, W8, W9 and W12), letters (W6), review sheets (W10), games (W12), structured programmes and exercises (W13 and W15) in facilitating the consolidation process were reported. An emphasis on the developmental aspect of user participation was evident. The meaning and importance of consolidation can be illustrated in the following responses:

Consolidation gives clients the feeling of being respected. Also, worker will appraise clients' effort and growth in the helping process and empower them. It is a symbolic practice to confirm clients' success and help them 'graduate'. (W10) 
and

Consolidation is a task of promoting user participation in the termination stage to enhance clients' awareness of the helping process and find out their readiness to treat their problems independently in the future. (W15)

Eight respondents (W3, W5, W6, W8, W9, W10, W12 and W14) acknowledged the importance of evaluating the effectiveness of the service provision at the termination stage. They had a strong sense in gathering clients' opinions in this area as shown in the following case:

I have sent letters to all my clients in order to collect their feedback and opinions on their development in the helping process, their future directions and my performance as their worker. The aim of this practice is to let them know that they have rights in criticizing the service. (W6)

Seven respondents (W4, W6, W7, W8, W9, W10 and W14) said that they have explained the formal channels of feedback and complaints in their OSW teams to their clients.

The findings showed that all respondents treated termination as an important process in their intervention with cases of high-risk youth. However, they tended to overlook clients' needs in knowing their rights (expressive participation) and focused more on clients' growth (developmental participation) in the termination process when they helped clients consolidate their experience learnt and informed them about formal channels for feedback and complaints. 


\section{Workers' Perceptions of User Participation and Clients' Growth}

Workers were asked to describe how they saw the growth of the clients through the promotion of user participation in the whole helping process. Two typical responses were:

User participation provides an insight to treat OSW clients as users instead of service recipients. The idea of user participation let clients have more says in the service provision and it cures the traditional imbalance working relationship in OSW. I think user participation protects clients'rights and also empowers them. I don't worry about this empowerment will affect the professionalism of social work. (W1)

and

User participation respects clients' rights and reduces the mystery of the service. If workers are conscious to educate their clients on user participation, the growth of clients could be incredible. (W5)

The findings also showed that the OSW workers were enthusiastic in promoting user participation in the helping process as they saw positive values in it. Their actual practice, however, was not systematic. Knowledge of and skills in promoting user participation influenced their actual practice at different stages of the intervention with the high-risk youth. It seems that strategic approaches should be developed in order to help workers practise user participation in different intervention stages more effectively. 


\section{Difficulties Encountered by Workers in Promoting User Participation}

There were some difficulties encountered by workers in promoting user participation in OSW service with high-risk youth. Seven respondents (W2, W5, W6, W7, W10, W12 and W15) felt that their knowledge of user participation was inadequate. Three (W2, W6 and W7) disclosed that they did not have a clear direction in promoting user participation and thought their practice was based on their own judgements and intuition.

Three main constraints emerged as affecting the promotion of user participation in the helping process as stated by the workers. Firstly, the workers' attributes themselves seemed critical. Six respondents (W1, W3, W11, W12, W13 and W14) suggested that workers might have resistance in promoting user participation, along the lines of this comment,

I think OSW workers are conservative in maintaining their superior roles in the helping process. They feel the teaching of user participation is time consuming. Also, the execution of user participation will affect the cost-effectiveness of the service provision. (W3)

The other nine respondents thought that workers were willing to promote user participation in the helping process, but they suffered from skill deficiency, diffidence and inadequate experience. The following is a typical example:

I don't know how to apply user participation systematically to my clients in regard to their stage of development. More training and sharing is 
needed to improve my skills in this area. (W7)

Secondly, client elements were also considered as an important determinant affecting the promotion of user participation. Here, the ideas of the respondents were controversial. Eight of them (W1, W2, W4, W5, W6, W8, W9 and W15) believed that clients were always ready to execute their rights as users while the rest had the opposite opinions. The latter suspected that clients lacked knowledge and experience in participation and they did not know how to participate even though the workers encouraged them to do so. Here as predicted, skepticism on the ability of high-risk youth to participate in the helping process, emerged. Factors such as their maturity and ability were raised in comments such as:

My client may not be mature enough to understand the importance of their participation. Even though they are old enough, they may not know how. (W3)

OSW clients adopt a dependent role in the helping process and their willingness to accept more active roles was unknown. (W11)

Thirdly, workload was also identified as a constraint in promoting user participation. Except W4, W13 and W14, all the other workers felt that the existing workload of OSW prohibited their full commitment to promote user participation.

The worker is expected to judge the extension, degree and applicability of user participation in different cases. Under the present situation without 
adequate support, it is a challenge to any worker's ability and experience.

To sum up, worker and client attributes and workload were considered as the three main sources of constraints affecting the promotion of user participation in the helping process with high-risk youth in OSW service. Also, some workers regarded clients' immaturity and inability, etc. as obstacles for the promotion of user participation in the helping process. Finding ways to minimize the impact of these constraints in order to help clients be more participatory in the service is needed.

\section{Clients’ Understanding of User Participation}

After introducing the concept of user participation to clients in the interviews, it was found that most understood the meaning of user participation in the helping process in terms of expressing opinions, asking questions, making choices and working together with workers. However, their knowledge of user participation in the helping process was vague even though they might have heard the term from the social workers and the mass media. Altogether, 11 respondents (E1, E2, E3, E4, E5, H2, H3, H4, H5, T3 and T4) defined user participation in OSW as ‘joining activities', two respondents (T1 and T2) expressed the term directly as 'being involved' and only two respondents (H1 and T5) interpreted it as 'having a say and choices in the helping process and making decisions jointly with the social worker'.

To further explore client respondents' perceptions of user participation, a checklist presenting some practical ideas of user participation was presented to help them evaluate their experience in the helping process. The results are shown in the 
Table 1.

'Making decision jointly' (with workers) was strongly felt by the client respondents. All 15 respondents were satisfied when they weighed their participation in making decision and they further elaborated that workers would respect their choices and they would not be pushed to change their choices. They reported that the worker's attitude in inviting their opinions was significant in determining their willingness to voice out their ideas. Nine respondents (E2, E3, H2, H4, H5, T2, T3, T4 and T5) highlighted that where the worker did not have respect and an open attitude in the helping process, they could not maintain their relationship with the worker. This response was typical:

My worker gives me a lot of chances in making decision and I feel that I am more mature and independent now. The learning process is similar to playing basketball. If you have more chances to practise, you will play better. (E3)

Even though the findings indicated workers were given relatively high scores in promoting user participation, from the comments of the respondents the actual practice in promoting user participation of the workers was diminished. When invited, most respondents could not give examples on how workers requested their participation in the helping process.

The findings reflected that workers paid relatively little attention to client status (58), rights and obligations (54), allowing clients to access to records (53) and 
involving them in evaluating the helping process (55). It is significant to note that even though the actual participation of clients in the helping process was slight, all respondents said that there were no real constraints affecting their participation. This inconsistency suggested that there was something much more important than the actual user participation practice, that is, the attitude of worker in involving clients in the helping process.

\section{Clients' Participation in the Helping Process}

Engagement Stage: All the respondents (E1 to E5) reported that their workers directly revealed their identity as an OSW worker to them in the first few contacts. Workers would give their name cards and introduce the services to them. E1 and E3 reported that they felt strange when an adult approached them in the streets. But they said that they felt comfortable when they knew the identity of the workers and kept in touch with them frequently as friends. All the respondents felt that they would not query the reasons behind the need to receive the OSW service, as they regarded chatting with and joining activities organized by the workers to be important. Expect E3, all the respondents agreed that their workers understood them sufficiently and were willing to share their concerns and issues with them. They felt workers were willing to listen to their situations, provide useful feedback and keep their information confidential.

E1 to E5 reported that they could voice their opinions to their workers without hesitation since the workers showed openness and willingness to respect different viewpoints. E2 and E5 said that the OSW workers seldom argued with them like their teachers and parents. All respondents said they trusted their workers, that they 
would allow them to make their own choices and did not insist on forcing them to follow their opinions. Even though their decisions might sometimes be socially undesirable, workers would still respect them.

Concerning clients' rights and status, only E1 reported that he knew his client status. He said that he knew his worker would write in his case file and hand it to a supervisor for comments. The other respondents were not informed clearly about their client status. E4 learned indirectly from his probation officer and school social worker that he was a client of the OSW team. When their client status and the existence of their case files were mentioned, E2, E3 and E5 did not contest the issues. It seems that clients were ready to know about their rights and status even in the engagement stage, as E2 stated:

I only knew what the worker informed me and I seldom took the initiative in asking further details. It doesn't matter. (E2)

In summary, all 5 respondents in the engagement stage were satisfied with the performance of their workers and they felt unconstrained in sharing their personal matters with workers. Although the sharing of information (such as client right) was not frequent, clients were ready to know about such information though they seldom took the initiative to ask. All respondents regarded counselling from and recreational activities organized by workers could enrich their daily life. Generally, they appreciated the effort of workers.

Helping Stage: In the helping stage, H3 and H5 reported that their situations 
became quite stable after worker's intervention. All 5 respondents recalled their problems and the ways of their workers helped. Below are two examples:

I have had some conflicts with my classmates. I decided to find someone to take revenge on them and my worker taught me lots of alternatives in dealing with the situation. My worker presented the possible consequences of my decision but he allowed me to have choices. Finally, the police caught me due to my involvement in a gang fight. My worker still forgave me and arranged legal help for me. Also, he negotiated with my school personnel for retaining my place. I hope that my worker will continue to provide his service to me and remind me to be good. (H1) and

The worker helps me improve the relationship with my family. She serves as the bridge in facilitating the communication in my family by contacting my parents and providing counseling and social skills training to me. My communication with my family has improved after her intervention. (H5)

It was found that all respondents in the helping stage had concrete future plans and they were willing to share with their workers in seeking advice and resources. They felt that their workers were eager to listen to their plans even though they might not be able to provide specific help. All respondents enjoyed the process of sharing their plans, since they felt that workers could show their concern open-mindedly. H1, H2, H4 and H5 knew that they should not voice unreasonable requests (e.g. borrowing money). They would accept worker's limitations in offering help set within constraints of daily life, such as difficulties in finding a school or job. 
Similar to the cases in the engagement stage, H1 to H5 stated that they could voice their opinions to their workers without hesitation. Since they trusted their workers, they felt free to express their opinions. All respondents agreed that their workers allowed them to make their own choices and did not push them to follow their instructions. Their experiences confirmed that the practice of user participation was significant in enhancing their change and learning. The following case is a good example:

I feel that I became mature under the guidance of my worker. My relationship with my family is improved. I have many chances in expressing my opinions and making decisions during the process. It may be the reason for me to learn a lot in the helping process. (H5)

The findings in this part revealed that all the respondents enjoyed the relationship with their workers. Although most of them could not recognize exactly the concept of participation in the helping process, they felt their workers were willing to share and accept their opinions and behaviours. Except H3, they all agreed that they had grown and changed after receiving the service.

Termination Stage: Among the five respondents in the termination stage, only T4 reported that he did not get a message of termination from his worker. The other four respondents had formal interviews with their workers in discussing the issue of termination and reviewed the past experience in receiving the service. T5 elaborated: 
I knew my entry into the service at the beginning as my worker told me and I was invited to make the decision in the process of leaving the service.

T2 and T3 had similar statements concerning the messages they received from their workers on termination:

The worker appreciates my growth in the past and he encourages me to be independent without his assistance in the future. (T3)

All respondents except $\mathrm{T} 4$ indicated their experience of the consolidation process, whereby instead of only an oral evaluation, a questionnaire was used. T1, T2, T3 and T5 gave consent to worker's suggestion of termination without resistance or asking for further service. T2 and T3 showed their understanding of the workers’ workload and the need to allocate more time to younger youths. T5 provided this positive statement concerning termination:

In the interview for termination, my worker gave me my file to read. I felt odd at first but after I finished reading, I appreciated much on my worker's effort in writing the diary for me in the past few years. The file recalled my memory, changes and development. I agreed with most of the contents in the file and I did not have an uncomfortable feeling in his writing of my history. (T5) 
When asked about the overall helping process, all the respondents (T1 to T5) felt that they were satisfied with the process and the performance of their workers. Although they did not know the formal channels to give feedback to the service, they expressed their opinions to their workers directly. Most clients in the termination stage felt that they could share their opinions with their workers. Genuineness, empathic understanding, acceptance and the keeping of confidentiality of workers were regarded as crucial factors for clients to express their opinions without reservation. Moreover, they all acknowledged their workers' effort in furnishing opportunities for their learning and respecting their choices in the helping process.

It is important to note that all the respondents stated that they had confidence to be independent after termination. They recognized positive changes and felt confident in facing the future after receiving the service. Sharing with workers about growth and changes (a primary element of user participation) had a significant contribution to their development.

In the past, I hung around in the streets at night and slept in the daytime. I did nothing but borrowing money from my friends and took drugs. But now I have stopped taking drugs, found a job and study in an evening school. I have become another person. My lifestyle is completely different. If I haven't met my worker, I think I would continue to take heroin. Without her encouragement and support, it would be really a hard task for me to detoxify my drug addiction. I have confidence that I won't disappoint my worker and relapse easily. (T3) 
The consolidation process in termination had created positive impacts on the respondents. They all felt that they had confidence to be independent and faced their future with their own effort. Most of the respondents had the feeling that, at termination, they had meaningfully participated in reviewing progress.

\section{Clients' Perceptions of User Participation and their Growth}

All 15 respondents indicated that they had positive changes after receiving the OSW service. Eight respondents (E1, E2, E3, H1, H2, T3, T4 and T5) said that their problems would deteriorate if they had not met the workers. Besides, respondents also reported positive learning from the workers including areas such as emotional control (E1, E5 and T5), communication and social skills (E2, H1 and H2), problem-solving skills (E3, E4, H5 and T1) and self-confidence (T3 and T4). They also stated that the workers stimulated their thinking and personal growth. Generally, the OSW service could fulfill their needs and provide adequate services to them. Only two, H2 and T3, commented that the workers were too busy and could not serve them effectively.

Overall, it seems that clients had only shallow ideas of user participation. Despite that, the intervention of their workers could help them grow. The findings revealed that clients were ready to learn more about participation at all stages of the helping process.

\section{Promotion of User Participation in Working with High-risk Youth: The How}

Although reservations have been raised in promoting the concept of user 
participation in working with high-risk youth who are perceived as immature, lacking of self-confidence and low in ability, the findings of this study show otherwise. The research findings indicated that user participation can be implemented fruitfully in the helping process with high-risk youth. All the workers interviewed had attempted to apply user participation in their practice, but they placed more emphasis on the developmental aspect of participation than on the expressive one (Parsloe, 1990). The study disclosed that the OSW workers were predisposed to involving clients in the helping process. While it was obvious that workers had the desire to practice user participation, it was not applied systematically. Based on an analysis of the findings, some principles for promoting expressive participation and developmental participation of OSW clients in the helping process were developed in order to assist the practice of user participation in OSW service. These principles were developed with reference to the stages of work and related work focuses in OSW service.

\section{Principles of Promoting Clients’ Participation}

There are three main work focuses in the Engagement Stage in OSW service, they are: (1) Clarification of OSW Service to Clients, (2) Clarification of Worker's Role, and (3) Informing Client Status.

(1) Clarification of OSW Service to Clients

\section{Principles for Promoting Clients’ Expressive Participation:}

1. A clear description of the purpose, objectives and mode of service delivery of the service should be provided to clients.

2. Clients should be ensured an adequate understanding of the possible consequences in receiving OSW service and the freedom to choose to stay in or not. 
Principle for Promoting Clients’ Developmental Participation:

1. Workers should recognize clients as experts on their own situation and workers have expertise in the process of professional intervention.

(2) Clarification of Worker's Role

Principles for Promoting Clients’ Expressive Participation:

1 The roles and responsibilities of OSW workers in the helping process should be clearly discussed with clients.

2 Clients have the right to note that OSW workers will treat them with dignity and respect, and will maximize confidentiality and self-determination.

Principles for Promoting Clients’ Developmental Participation:

1. Collaborative partnership between workers and clients should be emphasized.

2. Clients' active participation and self-determination in all aspects of the change effort should be promoted.

(3) Informing Client Status

Principles for Promoting Clients’ Expressive Participation:

1. Clients have the rights to know their status and the keeping of their information in the team's office.

2. Clients have the right to access their case files and workers have the responsibility to make the necessary preparation.

3. Clients should be clearly informed about their rights and responsibilities of receiving the service.

4. OSW workers have the responsibility to help clients obtain the 
appropriate services.

Principle for Promoting Clients’ Developmental Participation:

1. Recognizing the rights and power of clients as service users.

In the Helping Stage, the main work focuses are: (1) Problem/Need Assessment, (2) Formulation of Intervention Plan, and (3) Involvement in Intervention.

(1) Need/Problem Assessment

Principles for Promoting Clients’ Expressive Participation:

1. Clients' opportunities to have clear and accurate information about worker's assessment on their needs and problems should be maximized.

2. Clients should be involved in gathering and analyzing information for assessing and meeting their needs.

Principle for Promoting Clients’ Developmental Participation:

1. Involving clients to examine and assess their problems.

(2) Formulation of Intervention Plan

Principles for Promoting Clients’ Expressive Participation:

1. Clients should be involved in setting the working goals.

2. Consent from clients should be obtained for every action in the helping process.

Principles for Promoting Clients’ Developmental Participation:

1. Incorporating clients' strengths in the helping process.

2. Involving clients in exploring and analyzing available resources.

3. Helping clients clarify and operationalize the chosen working goals so as to formulate action plans. 
(3) Involvement in Intervention

Principles for Promoting Clients’ Expressive Participation:

1. Clients have the right to choose various alternative interventions.

2. Clients have the freedom to express their opinions, ask questions, make choices, and work together with workers.

Principles for Promoting Clients’ Developmental Participation:

1. Encouraging clients to identify and express their thinking and feelings in carrying out action plans.

2. Supporting clients' effort in building up productive and empowering connections with others.

3. Exploring and creating new resources for clients in their social and physical environments that can facilitate their empowerment by enhancing their sense of mastery.

4. Using case records for assessment with and empowerment of clients.

There are three work focuses in the Termination Stage: (1) Informing Termination, (2) Consolidation Work, and (3) Evaluation and Obtaining Feedback.

(1) Informing Termination

Principles for Promoting Clients’ Expressive Participation:

1. Clients should be clearly informed about ending of the service.

2. Clients have the right to determine the time frames of receiving the service.

Principles for Promoting Clients’ Developmental Participation:

1. Affirm the achievement of clients.

2. Decide with the clients on the need of continuous actions. 
(2) Consolidation Work

Principle for Promoting Clients’ Expressive Participation:

1. Clients should be helped reflecting and learning from their experience in the whole helping process.

\section{Principle for Promoting Clients’ Developmental Participation:}

1. Concluding the helping process through celebrating clients' successes, stabilizing their positive changes and encouraging them function independently.

(3) Evaluation and Obtaining Feedback

\section{Principles for Promoting Clients’ Expressive Participation:}

1. Clients should be involved in the evaluation process.

2. Clients' opinions on the service provision and workers' performance should be collected.

3. Clients have the right to know the channels to give feedback and make complaints.

Principle for Promoting Clients’ Developmental Participation:

1. Identifying with clients methods and strategies that they have used most effectively and empower them with knowledge that might be useful in meeting future challenges.

These principles can also be applied in other social casework settings. Internalizing these principles can help workers apply user participation systematically in their practice and increase their awareness of involving clients in the helping process. Similarly, they ought to be incorporated into the agency policy to guide quality practice. 
Furthermore, two implications for the work with high-risk youth in order to promote user participation are as follows:

\section{Cultivating Worker's Faith in User Participation}

The findings revealed that the most crucial factor to promote user participation in the helping process was the social worker himself/herself, not the nature of clients, workload, nor even the policy of the agency. No matter at what stages of the helping process, clients could take an active role if their workers allowed them to do so. It followed that workers' belief in the advantages of promoting user participation in the helping process with the clients was the crucial factor. Although clients may not have had a clear understanding of the concepts of user participation, they weighed workers' respect and acceptance as crucial elements in the working relationship. As the idea of implementing user participation by workers was shown to have positive effects on clients in the helping process, cultivation of this faith in workers are seen as imperative.

\section{Developing Strategies for Promoting User Participation}

It was shown that most OSW workers provided only brief introductions of the service and their roles to their clients in the engagement stage. In the helping stage, workers did not show a strong sense of involving clients in the formulation of an assessment and intervention plan in order to safeguard their rights (expressive participation) and enhance changes and learning (developmental participation). Clients felt that more could be done to train them to make decisions on personal matters if workers developed some strategies for maximizing clients' opportunities to participate. As workers' knowledge and experience in user participation are less 
than adequate in the field, besides observing the principles discussed above, developing strategies for promoting such practices is a priority.

\section{Conclusion}

This study attempted to explore the applicability of the concept 'user participation' in OSW service with high-risk youth who used to be judged as immature, lacking of confidence and low in ability.

The findings of this study revealed that although they describe it in different wordings, OSW workers had some basic understandings of the concept of user participation. In the helping process, they would clarify their roles at the engagement stage. However, they were not conscious of the need to involve clients in the assessment and intervention process in the helping stage. Even though they had promoted the practice of user participation with their clients, it was not applied systematically. Workers treated termination as an important stage for assisting clients to reflect on their growth (developmental participation) through helping them consolidate their learning from the helping experience. In terms of clients' growth, they generally saw positive impacts of practising user participation with high-risk youth.

On the side of the clients, the findings showed that although clients' knowledge of the concept of user participation was vague, they appreciated their workers' attitude in involving them in the helping process. It was found that even in the engagement stage, clients were ready to know more about their rights though they 
seldom asked. In the helping stage, clients were willing to share their plans with workers from whom they could seek advice and resources. Although they did not have concrete ideas of the concept of user participation, their experiences confirmed that the practice of user participation was significant in enhancing their change and learning. Similarly, although clients still did not have much idea of the concept of user participation at termination, they appreciated workers' help in consolidating their positive experience in the helping process. As a whole, despite their inadequate understanding of the concept of user participation, all client respondents reported positive changes after receiving help from the workers.

Based on analysing the findings of this study, two sets of working principles, one concerns promoting clients' expressive participation and the other concerns about promoting clients' developmental participation, are proposed. Furthermore, to cultivate workers' faith in and develop strategies for promoting user participation in work with high-risk youth should be pursued.

Traditional OSW service recognizes worker-client relationship is the crucial element in determining the success of the helping process. This study revealed that success is not just determined by the workers' good will, genuineness, sensible advice, concern and the availability of resources. The provision of opportunities for active participation of clients, such as expressing opinions, asking questions, making choices, sharing information and working together in the helping process, is also important. One significant conclusion of this study is that, opposed to the common skepticism, user participation can be promoted in work with high-risk youth who might otherwise be judged as immature, lacking of confidence and low in ability. 
Table 1: Client Respondents' Grading of their Participation in the Helping Process

\begin{tabular}{|c|c|c|c|c|c|c|c|c|}
\hline \multirow[t]{2}{*}{ Case } & \multicolumn{2}{|c|}{ Being Informed } & \multirow[t]{2}{*}{\begin{tabular}{|} 
Making Decision \\
Jointly
\end{tabular}} & \multicolumn{2}{|c|}{$\begin{array}{l}\text { Accessibility to } \\
\text { Information }\end{array}$} & \multicolumn{3}{|c|}{$\begin{array}{c}\text { Having Voices in the } \\
\text { Process }\end{array}$} \\
\hline & A & B & & $\mathrm{C}$ & D & $\mathrm{E}$ & $\mathrm{F}$ & $G$ \\
\hline E1 & 5 & 4 & 5 & 4 & 5 & 5 & 4 & 4 \\
\hline E2 & 4 & 3 & 5 & 4 & 4 & 5 & 5 & 3 \\
\hline E3 & 3 & 3 & 4 & 4 & 5 & 2 & 4 & 3 \\
\hline E4 & 3 & 2 & 4 & 4 & 3 & 4 & 3 & 3 \\
\hline E5 & 3 & 4 & 5 & 4 & 4 & 5 & 5 & 3 \\
\hline H1 & 4 & 4 & 5 & 3 & 5 & 5 & 4 & 4 \\
\hline $\mathrm{H} 2$ & 4 & 4 & 5 & 2 & 4 & 4 & 4 & 3 \\
\hline H3 & 4 & 4 & 4 & 4 & 4 & 4 & 4 & 4 \\
\hline $\mathrm{H} 4$ & 5 & 5 & 5 & 5 & 5 & 4 & 5 & 4 \\
\hline H5 & 4 & 4 & 5 & 3 & 4 & 5 & 5 & 4 \\
\hline $\mathrm{T} 1$ & 5 & 4 & 4 & 3 & 5 & 5 & 5 & 4 \\
\hline $\mathrm{T} 2$ & 4 & 3 & 4 & 2 & 3 & 4 & 3 & 3 \\
\hline T3 & 4 & 3 & 5 & 3 & 5 & 4 & 5 & 5 \\
\hline $\mathrm{T} 4$ & 3 & 4 & 4 & 5 & 3 & 5 & 5 & 4 \\
\hline $\mathrm{T} 5$ & 3 & 3 & 4 & 3 & 4 & 5 & 4 & 4 \\
\hline Total & 58 & 54 & 68 & 53 & 6 63 & 66 & 65 & 55 \\
\hline \multicolumn{9}{|c|}{ Legends: } \\
\hline \multicolumn{4}{|c|}{$\begin{array}{l}\text { A: Client Status } \\
\text { B: Rights \& Obligations } \\
\text { C: Personal Records } \\
\text { D: Worker's Intervention Plan }\end{array}$} & $\begin{array}{l}\text { E: Per } \\
\text { F: Sett } \\
\text { G: Fee } \\
\text { Meani } \\
3=\text { Fa }\end{array}$ & $\begin{array}{l}\text { Need } \\
\mathrm{f} \text { Work } \\
\mathrm{k} \text { on H } \\
\text { Score: } \\
=\text { Good } \\
\end{array}$ & $\begin{array}{l}\text { sessm } \\
\text { g Goa } \\
\text { jing } P \\
=\mathrm{Ver} \\
5=\mathrm{Ve}\end{array}$ & $\begin{array}{l}\text { ss } \\
\text { or; } 2 \\
\text { food }\end{array}$ & bor; \\
\hline
\end{tabular}




\section{References}

Adams, R. (1996). Social Work and Empowerment. London: Macmillan Press Limited.

Atkinson, J.M. and Elliott, L. (1994). 'Evaluations and Consumers', in Titterton, M. (ed.) Caring for People in the Community: The New Welfare, pp.153-67. London: Jessica Kingsley Publishers.

British Association of Social Workers (1980). Clients are Fellow Citizens: Report of the Working Party on Client Participation in Social Work. Birmingham: BASW.

Brohman, J. (1996). Popular Development: Rethinking the Theory and Practice of Development. U. S. A.: Blackwell Publishers Inc.

Capuzzi, D. and Gross, D.G. (eds.) (1996). Youth At Risk: A Prevention Resource for Counselors, Teachers, and Parents. (2/e) Alexandria, VA: American Counseling Association.

Carroll, M (1980). 'Collaboration with Social Work Clients: A Review of the Literature’, Child Welfare, LIX(7): 407-17.

Cheung Sha Wan Youth Integrated Service Centre, The Boys and Girls Clubs' Association of Hong Kong (1999). The Participation of Young People in Gangs. (in Chinese) Hong Kong: The Boys and Girls Clubs’ Association of Hong Kong.

Croft, S. and Beresford, P. (1994). 'A Participatory Approach to Social Work', in Hanvey, C. and Philpot, T. (eds.) Practising Social Work, pp.49-66. London: Routledge.

Fischer, C.T. and Brodsky, S.L. (1978). Client Participation in Human Services: The Prometheus Principle. New Jersey: Transaction Books.

Gunther, J. and Hawkins, F. (1996). Total Quality Management in Human Service Organizations. New York: Springer Publications.

Jessor, R.; Donovan, J.E. and Costa, F.M. (1991). Beyond Adolescence: Problem Behavior, and Young Adult Development. New York: Cambridge University Press.

Lee, F. (1994). 'Group Work with Youth-At-Risk', Asia Pacific Journal of Social Work, 4(2): 31-40.

Martin, L. (1993). Total Quality Management in Human Service Organizations. California: Sage Publications.

McWhirter, J.J.; McWhirter, B.T.; McWhirter, A.M. and McWhirter, E.H. (1998). At-Risk Youth: A Comprehensive Response - For Counselors, Teachers, Psychologists, and Human Service Professionals. London: Brook/Cole Publishing Company. 
National Association of Social Workers (1993). NASW Code of Ethics. Washington, DC: NASW.

Parsloe, P. (1990). A New Role for Clients in Social Welfare: Partnership, Participation, Consumerism and Decentralization. (Occasional Paper Series No. 1). Hong Kong: Department of Social Work, Hong Kong Baptist College.

Skelcher, C. (1996). 'Public Service Consumerism: Some Questions of Strategy', Community Development Journal, 31(1): 66-72.

Social Welfare Department (1998). The Five Year Plan for Social Welfare Development in Hong Kong - Review 1998. Hong Kong: Government Printer.

Tower, K.D. (1994). 'Consumer-centred Social Work Practice: Restoring Client Self-determination’, Social Work, 39(2): 191-96.

Wong, D.S.W. (1997). Longitudinal Case Study on the Deviation Process of Youth-at-risk. (in Chinese) Hong Kong: ELCHK North District Outreaching Social Work Team. 